\title{
Avaliar o quê, em arte?
}

\author{
Maria Betânia e Silva
}

\section{Resumo}

Refletir sobre processos de avaliação em arte, como disciplina escolar, é o objetivo desse texto. É parte de uma pesquisa histórica sobre o ensino de arte na cidade do Recife que teve como campo de investigação três escolas públicas, especificamente, nos anos sessenta aos oitenta do século passado. Utilizamos documentos oficiais do período, documentos escolares, depoimentos de professores e alunos. O estudo mostra que, naquele momento, as preocupações com o processo avaliativo diziam mais respeito às atitudes e comportamentos que ao processo de aprendizagem dos conteúdos específicos da arte devido às dificuldades em estabelecer critérios do como e o que avaliar em arte, presentes nos documentos oficiais e refletidos nas práticas pedagógicas dos professores.

Palvras-chave: ensino de arte, avaliação, práticas pedagógicas.

\section{Abstract:}

Reflect on assessment processes in art, such as school discipline, is the aim of this paper. It is part of a historical research on the teaching of art in the city of Recife, which was field research three public schools, specifically, in the sixties to the eighties of last century. We use official documents, of the period, school documents, interviews of teachers and students. The study shows that, at the time, concerns about the evaluation process of the specific contents of art due to the difficulties in establishing the criteria and how to evaluate art, gifts and official documents reflected in the pedagogical practices of teachers.

Keywords: teaching of art, evaluation, pedagogical practices. 
Determinar o valor, a importância. Calcular, estimar, julgar. Esses são alguns dos significados estabelecidos para o verbo avaliar em dicionários da língua portuguesa. Porém, a questão que trazemos aqui se direciona a $\operatorname{arte}^{1}$ na escola. Nesse sentido, outras indagações vêm à tona: como determinar o valor e a importância da arte? De que forma se pode calcular, estimar e julgar a arte? Como se mede em notas ou conceitos os aspectos subjetivos nas atividades realizadas pelos alunos?

Esse texto traz para o leitor parte de uma pesquisa histórica sobre o ensino de arte que tentou investigar como professores que trabalharam em escolas públicas ${ }^{2}$ da cidade do Recife avaliavam seus alunos em arte durante os anos 60 aos 80 do século passado.

Importante destacar que ao serem escolarizados os diferentes saberes são organizados em um tempo e espaço específicos ao próprio funcionamento da escola. Ordenados em unidades com carga horária anual, mensal, semanal e diária, esses saberes também possuem formas de avaliação ou verificação de aprendizagem onde, em geral, se atribuem notas em números ou conceitos. Essa prática tem atravessado a história da educação.

A avaliação é considerada um instrumento sancionador e qualificador e o sujeito da avaliação é o aluno e o objeto da avaliação são as aprendizagens adquiridas de acordo com objetivos mínimos estabelecidos para todos (ZABALA, 1998).

Quem define se o aluno está apto ou não a prosseguir o processo educacional escolar? A avaliação ou verificação da aprendizagem. Seu sentido é adquirido na medida em que se articula com um projeto pedagógico e com seu projeto de ensino. De acordo com Luckesi (2010) a avaliação, tanto no geral quanto no caso específico da aprendizagem, não possui uma finalidade em si; ela subsidia um curso de ação que visa construir um resultado previamente definido.

Mas, será que as práticas avaliativas têm sido articuladas a um projeto pedagógico? Será que as disciplinas escolares avaliam ou verificam a aprendizagem apenas pelo processo de "repetição" dos conteúdos trabalhados em sala de aula, um dos modelos utilizados na educação tradicional? Por vezes, o processo avaliativo se torna extremamente complexo e difícil de ser realizado.

\footnotetext{
1 Embora no decorrer da história do ensino de arte, no caso brasileiro, encontremos diferentes nomenclaturas para a disciplina escolar, inclusive no período a que se refere esta pesquisa, optamos por utilizar aqui o termo "arte" para identificar as disciplinas relacionadas a ela que faziam parte do currículo escolar nas escolas que foram investigadas. Isso significa que as disciplinas possuíam as seguintes denominações: artes plásticas, educação artística, música e canto orfeônico.

2 Três foram as escolas estudadas: Ginásio Pernambucano, Colégio Dom Bosco e Colégio de Aplicação, sendo duas estaduais e uma federal, respectivamente.
} 
Como, então, a escola avalia, por exemplo, o desenvolvimento dos sentidos, das sensações, das percepções, da criação, da expressão, da inovação, da postura, da presença no palco, da impostação da voz, dos movimentos do corpo, do humor etc.? Alguns desses elementos, comumente, não são ou são pouco trabalhados, observados ou desenvolvidos em outras disciplinas do currículo escolar, mas dizem respeito também ao ensino de arte.

Percorrendo a história da educação perceberemos que a escola ao ser instituída, durante o século XVII, ao longo do tempo, foi incorporando saberes científicos em oposição a outros saberes (CUNHA, 2003).

No século XIX, a crença que a atividade racional seria capaz de resolver todos os problemas humanos, garantir o progresso, a realização individual e proporcionar benefícios materiais a todos foi se solidificando e naquele contexto outros saberes que "escapavam" ao modelo do que se concebia "ciência" foi situado à margem, particularmente, nos currículos escolares.

Durante o século XIX a fundação do positivismo, por Auguste Comte (17981857), trouxe em seu bojo uma teoria da ciência que estabelecia três estados do saber: o teológico, o metafísico e o positivo. Mas, Comte defendia o saber positivo em detrimento dos outros, pois o positivismo rejeitava não somente as questões metafísicas e o conhecimento metafísico, como também a validade da intuição e qualquer tipo de conhecimento que não fosse relacionado à ligação entre os fatos (LUDWIG, 2009).

Seguindo essa direção os saberes científicos foram aos poucos se tornando a base de algumas disciplinas escolares e a concepção de ciência permaneceu durante muito tempo como um conhecimento sistematizado, resultante de determinados métodos e que pode ser comprovado. Mas, os saberes que extrapolavam esses limites, conseqüentemente, foram considerados menos importantes e menos essenciais para o desenvolvimento humano no espaço escolar. Como, então, medir, classificar, calcular aspectos subjetivos? De que forma se avalia o processo criativo? Como determinar o valor da experiência estética? Questões que até a contemporaneidade serão difíceis de estabelecer consensos. Mas, será que deveriam? Será que eram essas as preocupações com o sistema avaliativo em arte na escola por parte dos professores e daqueles que redigiam os documentos oficiais?

No período de nosso estudo, em questão, alguns documentos oficiais estabeleceram e definiram o tratamento avaliativo a ser dado à arte na escola. Por exemplo, desde os anos 60, no estado de Pernambuco, a lei 5695 que definiu a arte como uma prática educativa no currículo, expressou o seguinte para seu processo avaliativo: 
As práticas educativas propiciarão a expansão das potencialidades de criação, expressão, observação e ajustamento social, terão tratamento metodológico apropriado e não contarão para notas de aprovação, mas sua freqüência, com aproveitamento, será exigência condicional da efetivação da promoção (PERNAMBUCO, 1965).

Após a Reforma Educacional de 1971, que definiu a arte como atividade e passou a chamá-la educação artística no currículo nacional, diversos documentos foram publicados com o objetivo de orientar e esclarecer a compreensão da própria lei. A Resolução $\mathrm{n}^{\circ} 8$ também apresentou elementos de verificação da aprendizagem para a arte. "Nas atividades, a aprendizagem far-se-á, principalmente, mediante experiências vividas pelo próprio educando no sentido de que atinja, gradativamente, a sistematização de conhecimentos" (BRASIL, 1971).

Em anos seguintes outros documentos abordaram a mesma temática do como avaliar em arte. O documento intitulado Proposta Curricular (1975), que serviu de orientação para o ensino de arte até o final dos anos 80, também procurou estabelecer critérios para a avaliação, destacando o crescimento da criatividade do aluno. $\mathrm{O}$ documento registrou o seguinte:

A avaliação em expressão artística assume um caráter especial. Ela é utilizada como um meio e não como um fim em si mesma. Sua finalidade principal é o desenvolvimento da criatividade. Assim, o produto final da atividade não pode ser julgado do ponto de vista tradicional, de medir certo ou errado, falso ou verdadeiro, sim ou não, bonito ou feio. Durante o processo das atividades, o professor avalia o comportamento do aluno em relação ao crescimento da sua criatividade e lhe oferece oportunidade de enriquecimento, nunca de medir (PERNAMBUCO, 1975).

No final da década de 70, outro documento publicado continuou a definir o como a arte deveria ser avaliada. Enfatizando o objetivo da arte na escola como um processo e centrando o processo avaliativo nos opostos do interesse e do desinteresse, do feio e do bonito, do certo e do errado, o documento diz:

O trabalho deve se desenvolver sempre que possível por atividades e sem qualquer preocupação seletiva. A verificação da aprendizagem, nas atividades que visem especificamente à Educação Artística nas escolas de $1^{\circ}$ e $2^{\circ}$ graus, não se harmoniza também com a utilização de critérios formais. Essas atividades não visam à formação de artistas. Não faria sentido, pois, manter-se o aluno preso a uma opção na qual o seu desempenho não revela seu maior interesse, negando-lhe a oportunidade de outras experiências, e muito menos de impedir a promoção de série àquele que não apresente resultados satisfatórios 
em termos de produto: o desenho feio, a dança canhestra, a representação dissonante no grupo, o canto desafinado no coro. E isto porque a importância das atividades artísticas na escola reside no processo e não nos seus resultados (BRASIL, 1977).

A dificuldade em estabelecer critérios convincentes de avaliação para áreas que extrapolam o desenvolvimento do pensamento lógico, dos sentidos, das sensações, das emoções é uma questão polêmica e difícil de atingir um consenso, particularmente, dentro do modelo de estruturação em que a escola foi centrada, com base em saberes científicos.

Pelo menos desde os anos 60, do século XX, nos documentos oficiais citados, a avaliação em arte foi determinada pela freqüência, pelo comportamento, sem impedimento de promoção de série escolar, sem a necessidade de apresentação de resultados satisfatórios em termos de produto, sem contar para notas de aprovação, sem qualquer preocupação seletiva. Mas, alguns questionamentos se destacam: esta mesma sistemática de avaliação, apresentada nos documentos oficiais, também era atribuída às outras disciplinas do currículo? Se no caso da arte não fazia sentido manter o aluno preso a uma opção na qual o seu desempenho não revelava seu maior interesse, por que, então, prender o aluno em outras disciplinas se também elas não revelavam seu maior interesse? Por que prender o aluno em matemática, português, história ou geografia, se alguma dessas disciplinas não revelava o maior interesse do aluno, por exemplo? Por que esse tratamento somente seria relacionado ao ensino de arte?

Assim, diante do que foi registrado nos documentos oficiais, como funcionava, então, no cotidiano escolar, a sistemática de avaliação em arte nas escolas estudadas? Como faziam os professores para avaliarem seus alunos?

Inicialmente para música e canto orfeônico, no Colégio Dom Bosco, a sistemática de avaliação era realizada por meio de provas ou testes com o resultado registrado em conceitos. No próprio depoimento fornecido pela professora houve controvérsias na forma e definição da avaliação utilizada na disciplina. $O$ fato de não ter nota número era um dos motivos do não ter como avaliar o aluno. A professora afirmou que era mais fácil esse sistema, em outro momento ela disse que nunca deu certo. Observemos o porquê.

A ha! A avaliação era uma pequena prova (ênfase) só assim pra dizer que fazia prova, sabe? Fazia uma provinha, entende? Escrever um verso do Hino Nacional, (...) umas besteiras, uns testezinhos bem fáceis porque nota mesmo eles não tinham, não é? Educação Artística era conceito. Aí, como era conceito você não tinha como avaliar, botar 10, botar 9, botar 8, 7 em que? Você podia avaliar uma criança que canta? Cantar o Hino Nacional todo, botar 10, ora, não dava, 
né? Aí, era conceito. Conceito era diferente, conceito A, B, C. Aí, era mais fácil (professora de música e canto orfeônico do Colégio Dom Bosco).

Mesmo com o resultado final apresentado em forma de conceito, no final do ano ele era traduzido em nota número. Havia certa confusão em compreender ou atribuir o mesmo raciocínio da avaliação em nota número para a avaliação em nota conceito. Ou seja, qual nota conceito correspondia a qual nota número? Problemática que a escola não conseguiu resolver retornando ao uso das notas números. Disse-nos a professora:

(...) Agora, eles traduziam isso, os conceitos, mais adiante os conceitos eram traduzidos em nota, não é? Porque houve uma época em que houve uma confusão muito grande dos conceitos. Conceito A, qual era a nota do conceito A? De 8 a 10, B de 7 a 9, sei lá? Abaixo de 5 era conceito $\mathrm{C}$, mas, aí não demorou muito. Conceito nunca deu certo não. Deu certo em algumas coisas, mas, o conceito mesmo pra gente dar nota, não dava. Educação Artística nunca pôde ter nota, não podia ter. Você não pode dar uma nota para uma pessoa que desenha muito bem, outra pessoa não sabe nem pegar no lápis (professora de música e canto orfeônico do Colégio Dom Bosco).

Para as aulas de educação artística as notas eram dadas em notas números, mas não havia provas e testes. $\mathrm{O}$ aluno entrevistado explicou como funcionava,

Ah! Apresentações folclóricas valendo nota, apresentações artísticas (...) Ah! O sistema de avaliação era muito bom. 6 você passava, 7 tava aprovado, $7,8,9,10.5$ tava reprovado. Desistente o pai e a mãe tinha que vir. (a avaliação) pra arte, educação artística, eles tinham só a presença e o desempenho, não era curricular, mas, avaliativa, entendeu? (aluno do Colégio Dom Bosco).

No Colégio de Aplicação, desde sua fundação, a sistemática de avaliação era diferenciada de outras instituições escolares. Avaliava-se o aluno por atingir ou não os objetivos propostos pelo professor no decorrer do ano letivo, essa avaliação era apresentada em forma de pareceres descritivos que continham o percurso de desenvolvimento do aluno durante cada bimestre estudado. Essa forma de avaliar era unificada para todas as disciplinas do currículo, inclusive artes plásticas e música. Vejamos o que e como a professora avaliava seus alunos.

Era mais pela participação deles. Não era pela qualidade do trabalho, isso não podia fazer, qualidade do trabalho. Era pela participação, a avaliação era pela participação, eles sabiam. Sempre teve um resultado mais ou menos bom porque todos gostavam de fazer, só um ou outro era assim meio (...) mas a maioria participava bem 
mesmo. Participava, colaborava com a organização das coisas, fim da aula sempre guardava material, recolhia material (professora de artes plásticas do Colégio de Aplicação).

Os alunos, por sua vez, exemplificaram como eram esses pareceres e o que era avaliado.

(...) o resultado não era nota, era bom, regular, sofrível e deficiente. Em Artes tinha os trabalhos, tinha a pasta que era a produção, era fazer. Cada um tinha sua pasta e aí ia ver o que você fez. Era concluir as coisas, os trabalhos, o projeto que tava em andamento (reflexão) (...) (aluna do Colégio de Aplicação).

É, no caso de artes plásticas, eu me lembro que o conceito ele parecia privilegiar mais o que era a atitude de investimento do aluno do que a qualidade artística da produção. Então, eu tinha colegas, que tão vindo agora na mente (...) que eram muito, eram alunas muito aplicadas, mas que não tinham maiores habilidades pra desenho e pintura e que, no entanto, tinham B porque cumpriam com as tarefas, faziam com dedicação. É, as recuperações, eram mais no sentido de fazer o que não tinha feito. Então, era mais nessa direção. Eu nunca fiquei em recuperação, não conheço o processo. Mas, eu me lembro que havia uma espécie de vigilância com os alunos que não tinham interesse pela disciplina. (...) Eu lembro de alguns colegas ficarem em recuperação e ter que ir lá no horário pra refazer. (...) Funcionava mais como uma punição, você não trabalhou direito agora vai ter que trabalhar mais pra repor o tempo que não foi bem aproveitado. (...) no caso de artes plásticas eu não via nenhum tipo de atitude de reprovação, do conteúdo ser tratado como algo mensurável, não é, facilmente mensurável (aluno 1 do Colégio de Aplicação).

O terceiro aluno entrevistado apontou três critérios de avaliação que eram utilizados em arte. $\mathrm{O}$ primeiro era a freqüência às aulas, o segundo era a realização das atividades e o terceiro eram as atitudes dos alunos em sala de aula. Assim, ele descreveu,

(...) tinha que ter a freqüência, não é? A realização do trabalho, não o desempenho, não o desempenho. Por exemplo, se você realizasse todos os trabalhos você não ia ficar em recuperação. E tinha também atitudes (...). Um aluno muito agitado, muito mal comportado, ele recebia na caderneta uma observação. Porque o Colégio de Aplicação como sempre teve, nessa parte da disciplina dos alunos, algo mais flexível, menos rígido, a gente se soltava. Por quê? Você entra no Aplicação aos 10, 11 anos, naquela época a gente ia até os 14 no máximo 15. A gente tá em plena ebulição. Quando chegava o $3^{\circ}$ ano 
principalmente, que era a série mais complicada, hoje a $7^{\mathrm{a}}$ série, a gente estava com os hormônios borbulhando, isso fazendo, subindo pelas paredes e os professores subindo com a gente, entendeu? (...) era difícil (ênfase) e você chegava na aula de arte que é mais livre, que não tem prova, aí a gente queria entrar na brincadeira (aluno 2 do Colégio de Aplicação).

Nas aulas de música, na compreensão dos alunos, a avaliação era mais exigente e essa exigência refere-se ao tipo de ensino, à necessidade de dominar um instrumento, de fazer pesquisa. Porém, a professora de artes plásticas também desenvolvia trabalhos de pesquisa, mas observe que para o aluno o que se fazia em música era mais exigente. Ele relata:

No caso de música a coisa era mais exigente, talvez, pelo tipo de ensino que a gente tinha que dominar instrumento, era fazer pesquisa biográfica, tinha umas tarefinhas semanais fora da aula. Eu me lembro de pessoas terem que fazer a recuperação pra recuperar o que não tinha chegado no ponto, não é? Não me lembro bem de provas, alguma coisa, no caso de música, me lembro de prova prática, prova pública, tocar, sei lá, determinada música, codificar algum tipo de sons, ritmos que eram produzidos pela professora. Talvez nessa época de estudar grandes compositores da música clássica. É, eu tava lembrando agora dos trabalhos terem nota, mas eu acho que era evidente a diferença da avaliação dessas duas disciplinas pra outras disciplinas do currículo, essa coisa clássica de que (...) eu não lembro de alguém ser reprovado (ênfase) em artes plásticas ou música. Eu me lembro de alguns casos de recuperação, enfim, por aí (aluno 1 do Colégio de Aplicação).

No Ginásio Pernambucano, a avaliação consistia na produção de todos os trabalhos solicitados pelo professor e em exercícios feitos em sala de aula onde os alunos eram chamados ao quadro para realizar a atividade solicitada pelo professor. O professor e o aluno entrevistado descreveram como funcionava o processo de avaliação em arte:

Tudo provas. Eram quatro provas no semestre, quatro no segundo, avaliação no meio do ano, no fim do ano tinha uma prova. Mas, sempre eram provas. Avaliações nossas eram nessa faixa e (ênfase) grande parte dissertações, tinha que escrever. (...) (o professor de educação artística) escrevia muito no quadro e quando ele fazia os gráficos e os desenhos, todos eles desenhavam no quadro, os meninos faziam o rabisco e jogava no papel. Era um Deus nos acuda! Ele era um tipo de camarada que vivia exigindo desse jeito. Era ruim de nota também, não era muito fácil com as notas não. Mandava o menino fazer duas, três vezes um trabalho. Isso tá errado, que trabalho 
mais feio, sujo, vá fazer isso de novo. Quero não, aceito não, aceito não e de série, dia tal eu quero os trabalhos. Ai de você se não desse porque ele não fazia mais nada não, não tem mais prova não, é zero! Cadê o trabalho? Fez não? Mas, professor eu trago mais tarde, eu vou buscar na banca. Ah, sim, cadê tá aí? Me dê, ah! trouxe não? Zero. Acabou. O cara por causa disso ia ter problema mais adiante. Porque havia aquele critério da exigência e todo mundo cumpria direitinho (professor do Ginásio Pernambucano).

Era só de prova mesmo. Existiam as questões não havia, que eu me lembre, não havia prova, avaliação oral individual não, era só escrita (aluno do Ginásio Pernambucano).

Em seguida, o leitor acompanhará um quadro síntese que construímos com os critérios de avaliação utilizados no ensino de arte com base nas falas dos sujeitos entrevistados, sejam professores, sejam alunos com o que era avaliado na prática cotidiana de sala de aula e também o que foi estabelecido pelos documentos oficiais.

\section{Critérios de avaliação em arte}

\begin{tabular}{|l|l|l|}
\hline Documentos Oficiais & Professores & Alunos \\
\hline $\begin{array}{l}\text { Freqüência } \\
\text { Aproveitamento }\end{array}$ & $\begin{array}{l}\text { Freqüência } \\
\text { Desempenho }\end{array}$ & $\begin{array}{l}\text { Frequiência } \\
\text { Atitude de investimento do aluno }\end{array}$ \\
\hline $\begin{array}{l}\text { Sem preocupação seletiva } \\
\text { Comportamento }\end{array}$ & $\begin{array}{l}\text { Provas e testes } \\
\text { Participação }\end{array}$ & $\begin{array}{l}\text { Provas } \\
\text { Atitudes comportamentais }\end{array}$ \\
\hline Crescimento da criatividade & $\begin{array}{l}\text { Colaboração na organização do } \\
\text { material }\end{array}$ & Apresentações folclóricas e artísticas \\
\hline Experiências vividas & Produção dos trabalhos solicitados & Produção, fazer \\
\hline Sem contar p/notas de aprovação & Realização de exercícios em sala & Realização de atividades \\
\hline
\end{tabular}

Fonte: Quadro elaborado a partir dos documentos oficiais e dos depoimentos dos sujeitos.

Desse modo podemos observar que a freqüência e o aproveitamento foram elementos comuns tanto nas falas dos sujeitos quanto nos documentos oficiais analisados.

A participação e colaboração em sala de aula foram apresentadas somente pelos professores. A produção apontada pelos professores e também pelos alunos. O comportamento citado tanto nos documentos oficiais quanto no depoimento dos alunos.

Todos os documentos oficiais afirmaram que a arte na escola não poderia impedir a promoção do aluno para a série subseqüente, mas nenhum professor afirmou isso. Nas vozes dos alunos, também não houve afirmação de que a disciplina impedia a promo- 
ção de série, mesmo ficando em recuperação, eles não lembram alguém que tenha sido reprovado na disciplina.

Nas atas de resultados finais do Colégio Dom Bosco e também do Ginásio Pernambucano, observamos que das disciplinas que compunham o currículo, vários alunos atingiam notas acima de seis em todas elas, exceto matemática, por quatro décimos ou um ponto, e por isso foram impedidos de continuar na série escolar subseqüente. Já em outros casos, observamos que alguns alunos ficaram com a nota abaixo da média em educação artística e foram promovidos. Em outros casos, ocorreu do aluno ter ficado com a nota baixa em educação artística e outras disciplinas e foi retido sem avançar para a série subseqüente.

No Colégio de Aplicação, tivemos acesso a fichas individuais de auto-avaliação preenchidas pelos alunos. Essas fichas foram elaboradas com questões que dizem respeito ao desempenho individual em sala de aula, às atitudes de colaboração e ao trabalho coletivo. No diário de classe consultado não encontramos o resultado final dos alunos, pois só constavam as atividades realizadas a cada aula, pois os pareceres descritivos eram elaborados separadamente das cadernetas escolares e entregues aos pais no final de cada ano letivo.

Ao investigar os processos metodológicos utilizados pelos professores e as formas de veicular a arte no interior do espaço escolar podemos afirmar que cada escola possuía um modelo diferenciado. A dinâmica das aulas de arte era uma constante nas três escolas estudadas e muitas das atividades realizadas em sala de aula estavam diretamente relacionadas às experiências vivenciadas pelos professores em suas trajetórias individuais e nos espaços de formação profissional que os mesmos freqüentaram.

Por outro lado, a escola ao apropriar-se da produção artística desenvolvida pelos alunos utilizava-a como um marco diferencial de seu trabalho pedagógico para ser visto e apreciado pelo público escolar e pelas personalidades que freqüentavam a escola nas festas, em datas comemorativas e outros eventos promovidos por ela.

A dificuldade em estabelecer critérios do como e do que avaliar em arte nos documentos oficiais que refletiu na própria prática pedagógica do professor levou ao estabelecimento de elementos que diziam mais respeito às atitudes e comportamentos que ao processo de aprendizagem em arte. Assim, a freqüência do aluno, o seu comportamento, a realização de exercícios e atividades foram os principais critérios estabelecidos para serem observados nos processos avaliativos em arte, porém sem preocupação seletiva e sem contar para notas de aprovação.

Encontramos no cotidiano escolar do período estudado não um ensino de arte. Mas, "ensinos de artes". Cada um com singularidades e particularidades. Mesmo identi- 
ficando alguns elementos em comum nas práticas pedagógicas do professor, nas atividades dos alunos, na avaliação realizada em arte, é impossível afirmar a existência de uma uniformidade no ensino de arte nas escolas.

De um lado, a diversidade de compreensões, de ensinos, de práticas e de formas de avaliar não podia estar desconectada do período social, político e econômico que se vivia no país. A arte utilizada como técnica, naquele momento, reforçava também o projeto educacional tecnicista implantado no período. A arte direcionada aos que tinham "dom", "aptidão" e "talento" excluía os que não se encaixavam nesse perfil. A arte utilizada para festas cívicas e folclóricas reforçava o projeto ditatorial não só de massificação da população, mas do "engrandecimento" do sistema de governo, de amenização da repressão que se vivia no período, de distanciamento da arte que era produzida e veiculada, pelo menos, pelas vanguardas artísticas em outras instâncias sociais.

De certa forma, as marcas da ditadura militar foram impressas no tempo. A diversidade de ensinos de artes mostrou que a escola, em seu processo de socialização e veiculação dos saberes, se apropria, reconfigura, inventa, produz outros sabres que não necessariamente advém do conhecimento científico. A intensa variedade de saberes que a escola promoveu em seu cotidiano favoreceu uma dinâmica própria de cada instituição escolar, mas também veiculou modos de ver, compreender e fazer arte que atravessaram o tempo e contribuíram para a formação das gerações seguintes.

\section{Referências bibliográficas}

BRASIL. Ministério da Educação e Cultura. A Lei 5692 de 1971 e o Ensino de primeiro grau - Série Ensino Fundamental.

BRASIL. Conselho Federal de Educação. Parecer CFE n540/77 - CE de $1^{\circ}$ e $2^{\circ}$ graus. Aprovado em 10/02/77 (Processo s/n). Sobre o tratamento a ser dado aos componentes curriculares previstos no art. $7^{\circ}$ da Lei nº5692/71.

CUNHA, Marcus V. da. A escola contra a família. In: LOPES, Eliane.M.T.; FARIA FILHO, Luciano M.; VEIGA, Cynthia G. 500 anos de educação no Brasil. Belo Horizonte: Autêntica, 2003, p.447-468.

LUDWIG, Antonio Carlos Will. Fundamentos e prática de metodologia científica. Petrópolis: Vozes, 2009.

LUCKESI, Cipriano Carlos. Gestão do currículo. Verificação ou avaliação: o que prati- 
ca a escola? Disponível em: http://www.ccv.ufc.br/newpage/conc/seduc2010/seduc_dir/ download/avaliacao1.pdf

PERNAMBUCO. Lei no 5695/65. Institui o Sistema Estadual de Educação de Pernambuco. Assembléia Legislativa. Governo do Estado de Pernambuco, 1965.

PERNAMBUCO. Secretaria de Educação e Cultura. Departamento de Ensino. Divisão de Ensino de $1^{\circ}$ e $2^{\circ}$ graus. Proposta Curricular - Ensino de $1^{\circ}$ grau - Comunicação e Expressão, 1975.

PERNAMBUCO. COLÉGIO DOM BOSCO. Livros de Atas de Resultados Finais, década de 1960, 1970, 1980.

PERNAMBUCO. GINÁSIO PERNAMBUCANO. Livros de Atas de resultados finais, década de 1960, 1970.

PERNAMBUCO. COLÉGIO DE APLICAÇÃO. Fichas Individuais de Auto-avaliação, década de 1980.

PERNAMBUCO. COLÉGIO DE APLICAÇÃO. Fichas individuais de avaliação, décadas de 1970, 1980.

PERNAMBUCO. COLÉGIO DE APLICAÇÃO. Diários de Classe, década de 1970.

\section{SITES}

http://www.dicionarioweb.com.br/avaliar.html Visita em 05.02.2012

http://www.lexico.pt/avaliar/ Visita em 05.02.2012

http://www.dicionarioinformal.com.br/significado/avaliar/2612 Visita em 05.02.2012

http://www.dicio.com.br/avaliar/ Visita em 05.02.2012

ZABALA, A. A prática educativa: como ensinar. Porto Alegre: Artmed, 1998. 